\title{
A New Scoring System for Predicting Short-term Outcomes in Critically-ill Acute Decompensated Heart Failure
}

\section{Ran Mo}

Fu Wai Hospital

Li-tian Yu ( $\square$ yulitian138@hotmail.com )

Emergency and Intensive Care Center, State Key Laboratory of Cardiovascular Disease, Fuwai Hospital, National Center for Cardiovascular Diseases, Chinese Academy of Medical Sciences and Peking Union Medical College, No. 167 Beilishi Road, Xicheng District, Beijing, People's Republic of China.

\section{Hui-qiong Tan}

Fu Wai Hospital

\section{Yang Wang}

Fu Wai Hospital

Yan-min Yang

Fu Wai Hospital

Yan Liang

Fu Wai Hospital

Jun Zhu

Fu Wai Hospital

\section{Research Article}

Keywords: acute decompensated heart failure, scoring system, prognosis

Posted Date: January 15th, 2021

DOI: https://doi.org/10.21203/rs.3.rs-145245/v1

License: (c) (i) This work is licensed under a Creative Commons Attribution 4.0 International License. Read Full License 


\section{Abstract}

Background: Acute decompensated heart failure (ADHF) contributes millions of emergency department (ED) visits and it is associated with high in-hospital mortality. The aim of this study was to develop and validate a multiparametric score for critically-ill ADHF patients.

Methods: In this single-center, retrospective study, a total of 1268 ADHF patients were enrolled and divided into derivation $(n=1014)$ and validation $(n=254)$ cohorts. The primary endpoint was any inhospital death, cardiac arrest or utilization of mechanical support devices. Logistic regression model was preformed to identify risk factors and build the new scoring system. The assigning point of each parameter was determined according to its $\beta$ coefficient. The discrimination was validated internally using $C$ statistic and calibration was evaluated by the Hosmer-Lemeshow goodness-of-fit test.

Results: We constructed a predictive score based on six significant risk factors [systolic blood pressure (SBP), white blood cell (WBC) count, hematocrit (HCT), total bilirubin (TBIL), estimated glomerular filtration rate (eGFR) and NT-proBNP]. This new model was computed as $(1 \times \mathrm{SBP}<90 \mathrm{mmHg})+$ $\left(2 \times \mathrm{WBC}>9.2 \times 10^{9} / \mathrm{L}\right)+(1 \times \mathrm{HCT} \leq 0.407)+(2 \times \mathrm{TBIL}>34.2 \mu \mathrm{mol} / \mathrm{L})+\left(2 \times \mathrm{eGFR}<15 \mathrm{ml} / \mathrm{min} / 1.73 \mathrm{~m}^{2}\right)+$ $(1 \times N T p r o B N P \geq 10728.9 \mathrm{ng} / \mathrm{ml})$. The $\mathrm{C}$ statistic for the new score was $0.758(95 \% \mathrm{Cl} 0.667$ to 0.838$)$ higher than APACHE $\triangle, A H E A D$ and ADHERE score. It also demonstrated good calibration for detecting high-risk patients in the validation cohort $\left(\chi^{2}=6.681, p=0.463\right)$.

Conclusions: The new score including SBP, WBC, HCT, TBIL, eGFR and NT-proBNP might be used to predict short-term prognosis of critically-ill ADHF patients.

\section{Background}

Heart failure (HF) is an advanced manifestation of various cardiovascular diseases responsible for several million hospitalizations worldwide, imposing a heavy economic burden ${ }^{[1]}$. Presence of HF generally implies poor prognosis, especially in patients who are admitted for acute decompensated heart failure. Recent data show that the in-hospital mortality for ADHF patients is $3 \%$ and the rehospitalization rate exceeds $50 \%$ within six months ${ }^{[2-4]}$. According to the latest American college of cardiology (ACC) guidelines, it is important for the initial evaluation of the clinical trajectory of ADHF. The identification of a high-risk status at admission may help to allocate limited hospital resources and discuss the appropriate goals of care ${ }^{[5]}$. Therefore, accurately assessing the severity and risk timely can be beneficial for patients with $\mathrm{ADHF}^{[6]}$.

Several risk stratification systems have been published previously. Unfortunately, there are several limitations of these systems. First, few of them focused on a contemporary intensive care unit (ICU) population with ADHF. Second, the existing risk assessment tools for inpatients with ADHF are often complex and are uniformly underutilized. Third, the tools emphasized clinical and laboratory variables but did not include echocardiographic measures and emerging plasma biomarkers ${ }^{[7]}$. Being universally 
available as a prime investigation for cardiac assessment, echocardiography carries a pivotal role in daily practice, particularly in managing ADHF patients. Finally, a recent study demonstrated that clinical care risk scores established to predict the prognosis in unselected ICU patients performed poorly in CICU with $A D H F$, emphasizing the need to develop improved tools for risk stratification among critically-ill ADHF patients ${ }^{[8]}$. The aim of this present study was to develop and validate a novel clinical scoring model to predict short-term adverse outcomes in a Chinese population of patients with critically-ill ADHF and compare it with the existing systems, such as the Acute Physiology and Chronic Health Evaluation(APACHE) system ${ }^{[9]}$, AHEAD score ${ }^{[10]}$ and ACUTE HF score ${ }^{[11]}$.

\section{Methods}

\subsection{Study population}

Clinical data were collected from 1268 patients with ADHF who were admitted to ICU from the emergency department (ED) at Fuwai hospital between January 2014 and December 2018. All participants met the most recent European guidelines for the diagnosis of acute heart failure ${ }^{[12]}$. Critically-ill ADHF was defined as exacerbation of chronic HF (CHF) with worsening symptoms sufficient to be admitted to intensive care. Exclusion criteria were known diagnoses with malignancy. Patients with ST-segment elevation myocardial infarction and non ST-segment elevation myocardial infarction were also excluded because TIMI score was established and extensively used in these patients and reperfusion treatment itself played an important role on the prognosis. However, patients with comorbid coronary heart disease and chronic HF who were hospitalized for exacerbation of $\mathrm{CHF}$ without indications for reperfusion therapy were also included in this study. All data were retrospectively obtained from Fuwai hospital electronic medical records. The study was approved by the ethics committee of Fuwai Hospital and was conducted in accordance with the Declaration of Helsinki.

\subsection{Data collection and endpoints}

For each patient, baseline information on admission was obtained including demographic data, baseline health status, Glasgow coma scale (GCS), body mass index (BMI), vital signs and comorbidities by reviewing their medical records. The presence of atrial fibrillation (AF) and bundle branch block (BBB) were measured with 12-lead electrocardiography and pleural effusion was determined by chest X-ray. Left ventricular ejection fraction (LVEF) and estimated pulmonary arterial systolic pressure (PASP) were assessed by using echocardiography (General Electric, USA). The participant's worst values of blood laboratory tests during the initial 24-hours were recorded including arterial $\mathrm{pH}, \mathrm{PaO}_{2}$, actual bicarbonate $(A B)$, lactate concentration, serum sodium, serum potassium, white blood cell (WBC) count, hemoglobin $(\mathrm{Hb})$ concentration, hematocrit, international normalized ratio (INR), D-dimer concentration, total bilirubin, serum creatinine, serum uric acid (SUA), high-sensitivity troponin I (hs-TNI) and N-terminal pro-B-type natriuretic peptide (NT-proBNP). Estimated glomerular filtration rate was calculated using the Chinese version of the MDRD equation ${ }^{[13]}$. 
The main outcome of this analysis was a composite endpoint defined as: (1)in-hospital mortality; (2)inhospital cardiac arrest during the admission; (3)utilization of mechanical support devices during the hospitalization which included intra-aortic balloon pumps (IABP) and extracorporeal membrane oxygenation (ECMO). We also collected the information about patients who had listed for heart transplantation ( $\mathrm{HTx})$.

\subsection{Statistical analysis}

For patients' background data, categorical variables were expressed as frequencies (percentages), and continuous variables were expressed as means \pm standard deviations or medians with quartiles depending on their normality. Normality was assessed using the Shapiro-Wilk W-test.

Participants were divided into derivation $(n=1014)$ and validation $(n=254)$ cohorts according to the order of admission to ED. The comparison of the baseline data indicated that the distribution of age and occurrence of endpoint agreed well between the two cohorts but the validation cohort had marginally more female patients, more patients with AF and higher NT-proBNP concentration. Some thresholds for categorical variables were adopted as commonly used in clinical treatment including heart rate (HR), respiratory rate (RR), $\mathrm{AB}$ and $\mathrm{PaO}_{2}$ whereas age, $\mathrm{pH}$ and hs-TNI were considered as continuous variables. Participants were divided into different groups based on the optimal cut-off values of lactate level, serum sodium, WBC, HCT, TBIL, SUA, D-dimer and INR which were determined by respectively performing receiver-operating characteristic $(\mathrm{ROC})$ curve analyses. Patients were defined as underweight by $\mathrm{BMI}<$ $18.5 \mathrm{~kg} / \mathrm{m}^{2}$, normal by $18.5 / \mathrm{kg} / \mathrm{m}^{2} \leq \mathrm{BMI}<24 \mathrm{~kg} / \mathrm{m}^{2}$, overweight by BMI $\geq 24 \mathrm{~kg} / \mathrm{m}^{2}$ and obese by BMI $\geq 30 \mathrm{~kg} / \mathrm{m}^{2}$. Serum potassium $<3.5 \mathrm{mmol} / \mathrm{L}$ was defined as hypokalemia and potassium $>5.5 \mathrm{mmol} / \mathrm{L}$ was defined as hyperkalemia. The cut-off levels for anemia were hemoglobin $<130 \mathrm{~g} / \mathrm{L}$ in men and $<$ $120 \mathrm{~g} / \mathrm{L}$ in women, whereas that for NT-proBNP were determined by quartiles. PASP $>30 \mathrm{mmHg}$ was recorded as increased pulmonary artery pressure. The thresholds for eGFR were in accordance with Kidney Outcomes Quality Initiative guidelines, which classified participants into five stages (eGFR $\geq 90$, $60 \leq \mathrm{eGFR}<90,30 \leq \mathrm{eGFR}<60,15 \leq \mathrm{eGFR}<30$ and eGFR $<15 \mathrm{ml} / \mathrm{min} / 1.73 \mathrm{~m}^{2}$ ). Three subgroups based on LVEF were identified: HF with reduced ejection fraction (HFrEF, LVEF $<40 \%$ ), HF with middle-range ejection fraction (HFmrEF, LVEF 40\%-49\%) and HF with preserved ejection fraction (HFpEF, LVEF $\geq 50 \%$ ). The predictive power of patients' characteristics for the short-term adverse outcomes was computed using the univariate logistic regression and described by odds ratios (ORs) and their $95 \%$ confidence intervals. Then, the statistically significant predictors identified by univariate analysis were entered into the multivariate logistic regression model with a forward stepwise selection algorithm. Using a method of $\beta$-coefficient-based weights similar to that used for the Framingham risk score ${ }^{[14]}$, the assigning weight of each predictor was determined according to the $\beta$ coefficient in the multivariate logistic regression model to develop a novel scoring system. Subsequently, in order to test the prognostic power of the new score, the ROC methodology was adopted both in derivation and validation groups. The discriminative capacity of the new score was quantified with C-statistic while calibration was graphically evaluated by the Hosmer-Lemeshow goodness-of-fit test. 
The software package SPSS version 25.0 (IBM Corporation, New York, NY, USA) was utilized for statistical analysis. All statistical tests were 2 -tailed, with a p value $<0.05$ considered statistically significant. Graphs were generated using the software GraphPad Prism 8.0.

\section{Results}

\subsection{Baseline characteristics}

The baseline characteristics of derivation and validation cohorts with critically-ill ADHF were summarized in Table 1. For both groups, the gender, age distribution and risk of adverse outcomes were comparable without significant difference. Of the 1268 patients enrolled, 873 were male with a median age of 58( \pm 17) years, among whom the elderly accounted for $17.9 \%$. The proportion of HFrEF was $62.3 \%, 13.9 \%$ for HFmrEF and $23.8 \%$ for HFpEF. Coexisting atrial fibrillation was observed in $35.6 \%$ patients and pleural effusion was identified in $31.9 \%$ of the participants. 
Table 1

Baseline characteristics and incidence of endpoint events

\begin{tabular}{|c|c|c|c|}
\hline Variable & Value & $\begin{array}{l}\text { Derivation cohort }(n= \\
\text { 1014) }\end{array}$ & $\begin{array}{l}\text { Validation cohort( } \mathrm{n}= \\
254)\end{array}$ \\
\hline Gender(men) & $873(68.8 \%)$ & $709(69.9 \%)$ & $164(64.6 \%)$ \\
\hline Age(years) & $58 \pm 17$ & $58 \pm 17$ & $58 \pm 17$ \\
\hline Age $\geq 75$ years & $227(17.9 \%)$ & $179(17.7 \%)$ & $48(18.9 \%)$ \\
\hline $\mathrm{BMI}\left(\mathrm{kg} / \mathrm{m}^{2}\right)$ & $23.90 \pm 4.50$ & $24.05 \pm 4.50$ & $23.56 \pm 4.86$ \\
\hline Glasgow coma scale & $14.8 \pm 0.85$ & $14.8 \pm 0.86$ & $14.7 \pm 0.86$ \\
\hline Temperature $\left({ }^{\circ} \mathrm{C}\right)$ & $36.35 \pm 0.42$ & $36.33 \pm 0.43$ & $36.40 \pm 0.38$ \\
\hline $\mathrm{SBP}(\mathrm{mmHg})$ & $115.06 \pm 20.46$ & $115.86 \pm 20.37$ & $111.88 \pm 20.49$ \\
\hline HR (BPM) & $80 \pm 19$ & $80 \pm 19$ & $81 \pm 21$ \\
\hline $\operatorname{RR}\left(\min ^{-1}\right)$ & $19 \pm 3$ & $19 \pm 3$ & $19 \pm 3$ \\
\hline Diabetes mellitus(\%) & $342(27.0)$ & $273(26.9)$ & $69(27.2)$ \\
\hline Smoking(\%) & $632(49.8)$ & $512(50.5)$ & $120(47.2)$ \\
\hline Alcohol use(\%) & $509(40.1)$ & $412(40.6)$ & $97(38.2)$ \\
\hline Arterial pH & $7.45 \pm 0.11$ & $7.44 \pm 0.11$ & $7.46 \pm 0.05$ \\
\hline $\mathrm{PaO}_{2}(\mathrm{mmHg})$ & $87.46 \pm 26.79$ & $88.01 \pm 25.38$ & $85.30 \pm 31.65$ \\
\hline $\mathrm{AB}(\mathrm{mmol} / \mathrm{L})$ & $24.41 \pm 4.40$ & $24.44 \pm 4.43$ & $24.30 \pm 4.33$ \\
\hline Lactic acid(mmol/L) & $1.82 \pm 1.15$ & $1.83 \pm 1.20$ & $1.78 \pm 1.03$ \\
\hline Serum sodium(mmol/L) & $136.06 \pm 5.05$ & $136.35 \pm 5.08$ & $134.92 \pm 4.76$ \\
\hline $\begin{array}{l}\text { Serum } \\
\text { potassium(mmol/L) }\end{array}$ & $4.05 \pm 0.58$ & $4.06 \pm 0.58$ & $4.02 \pm 0.60$ \\
\hline Leukocyte count $\left(\times 10^{9} / \mathrm{L}\right)$ & $7.8 \pm 3.5$ & $7.8 \pm 3.5$ & $8.0 \pm 3.7$ \\
\hline Hemoglobin(g/L) & $134.9 \pm 24.7$ & $135.8 \pm 24.3$ & $131.5 \pm 25.8$ \\
\hline Hematocrit & $0.409 \pm 0.071$ & $0.411 \pm 0.070$ & $0.398 \pm 0.074$ \\
\hline INR & $1.39 \pm 0.89$ & $1.37 \pm 0.96$ & $1.46 \pm 0.58$ \\
\hline D-dimer(mg/l) & $2.24 \pm 3.49$ & $2.21 \pm 3.83$ & $2.35 \pm 2.92$ \\
\hline \multicolumn{4}{|c|}{$\begin{array}{l}\mathrm{BMI}=\text { body mass index; } \mathrm{SBP}=\text { systolic blood pressure; } \mathrm{HR}=\text { heart rate; } \mathrm{RR}=\text { Respiratory rate; } \mathrm{AB}= \\
\text { actual bicarbonate; hs-TNI = high-sensitivity troponin } \mathrm{I} ; \mathrm{NT} \text {-proBNP = N-terminal pro-B-type natriuretic } \\
\text { peptide; } \mathrm{LVEF}=\text { left ventricular ejection fraction; } \mathrm{PASP}=\text { pulmonary arterial systolic pressure; IABP = } \\
\text { intra-aortic balloon pump; } \mathrm{ECMO}=\text { extracorporeal membrane oxygenation. }\end{array}$} \\
\hline
\end{tabular}




\begin{tabular}{|c|c|c|c|}
\hline Variable & Value & $\begin{array}{l}\text { Derivation cohort( } \mathrm{n}= \\
\text { 1014) }\end{array}$ & $\begin{array}{l}\text { Validation cohort }(\mathrm{n}= \\
\text { 254) }\end{array}$ \\
\hline Total bilirubin $(\mu \mathrm{mol} / \mathrm{L})$ & $29.5 \pm 25.3$ & $29.7 \pm 24.0$ & $28.5 \pm 29.9$ \\
\hline Uric acid( $\mu \mathrm{mol} / \mathrm{L})$ & $540.4 \pm 196.3$ & $532.1 \pm 191.0$ & $573.4 \pm 213.3$ \\
\hline $\mathrm{Hs}-\mathrm{TNI}(\mu \mathrm{g} / \mathrm{L})$ & $0.045(0.02 \sim 0.10)$ & $0.04(0.02 \sim 0.10)$ & $0.06(0.02 \sim 0.13)$ \\
\hline NT-proBNP(ng/ml) & $\begin{array}{l}5478.2(2286.5 \sim \\
11957.3)\end{array}$ & $\begin{array}{l}4966.5(2171.3 \sim \\
10728.9)\end{array}$ & $\begin{array}{l}\text { 6821.2(3028.5 } \\
17569.3)\end{array}$ \\
\hline \multicolumn{4}{|l|}{ LVEF } \\
\hline HFrEF (yes, \%) & 790(62.3) & $629(62.0)$ & $161(63.4)$ \\
\hline HFmrEF(yes, \%) & 176(13.9) & 141(13.9) & $35(13.8)$ \\
\hline HFpEF(yes, \%) & $302(23.8)$ & $244(24.1)$ & $58(22.8)$ \\
\hline PASP > 30 mmHg(\%) & $590(46.5)$ & $456(45.0)$ & 134(52.8) \\
\hline \multicolumn{4}{|l|}{$\operatorname{eGFR}\left(\mathrm{ml} / \mathrm{min} / 1.73 \mathrm{~m}^{2}\right)$} \\
\hline eGFR $\geq 90(\%)$ & $271(21.4)$ & 232(22.9) & $39(15.3)$ \\
\hline $60 \leq \mathrm{eGFR}<90(\%)$ & $375(29.6)$ & $283(27.9)$ & $92(36.2)$ \\
\hline $30 \leq \mathrm{eGFR}<60(\%)$ & $489(38.6)$ & $383(37.8)$ & $106(41.7)$ \\
\hline $15 \leq \mathrm{eGFR}<30(\%)$ & 109(8.6) & $97(9.6)$ & $12(4.7)$ \\
\hline eGFR<15(\%) & $24(1.9)$ & 19(1.8) & $5(2.0)$ \\
\hline Atrial fibrillation(\%) & $451(35.6)$ & $349(34.5)$ & $102(40.2)$ \\
\hline Pleural effusion(\%) & 404(31.9) & $322(31.8)$ & $82(32.3)$ \\
\hline \multicolumn{4}{|l|}{ Outcomes } \\
\hline Composite endpoint(\%) & $181(14.3)$ & 144(14.2) & $37(14.6)$ \\
\hline In-hospital death(\%) & 117(9.2) & $93(9.2)$ & 24(9.4) \\
\hline $\begin{array}{l}\text { In-hospital cardiac } \\
\text { arrest(\%) }\end{array}$ & $48(3.8)$ & $41(4.0)$ & $7(2.8)$ \\
\hline $\begin{array}{l}\text { Applications of IABP or } \\
\text { ECMO(\%) }\end{array}$ & $16(1.3)$ & $10(1.0)$ & $6(2.4)$ \\
\hline Heart transplantation(\%) & $45(3.5)$ & $32(3.2)$ & $13(5.1)$ \\
\hline \multicolumn{4}{|c|}{$\begin{array}{l}\mathrm{BMI}=\text { body mass index; } \mathrm{SBP}=\text { systolic blood pressure; } \mathrm{HR}=\text { heart rate; } \mathrm{RR}=\text { Respiratory rate; } \mathrm{AB}= \\
\text { actual bicarbonate; hs-TNI = high-sensitivity troponin I; NT-proBNP = N-terminal pro-B-type natriuretic } \\
\text { peptide; } \mathrm{LVEF}=\text { left ventricular ejection fraction; } \mathrm{PASP}=\text { pulmonary arterial systolic pressure; IABP = } \\
\text { intra-aortic balloon pump; ECMO = extracorporeal membrane oxygenation. }\end{array}$} \\
\hline
\end{tabular}


During hospitalization, the primary endpoint occurred in 181 patients $(14.3 \%)$ with 117 death $(9.2 \%)$. The heart transplantation occurred in $3.5 \%$ of the patients.

\subsection{Logistic regression and model establishment}

Univariate analysis was performed in derivation cohort using the univariate logistic regression model and included the following 29 parameters: age, elderly, sex, BMI, GCS, temperature, SBP, heart rate, RR, arterial $\mathrm{pH}, \mathrm{PaO}_{2}, \mathrm{AB}$, lactic acid, serum sodium, potassium, WBC, Hb, HCT, TBIL, SUA, eGFR, D-dimer, INR, NTproBNP, hs-TNI, LVEF, PASP, existence of AF, pleural effusion and BBB. All variates except age, sex, temperature, $\mathrm{RR}$, arterial $\mathrm{pH}, \mathrm{PaO}_{2}$, hs-TNI, LVEF, AF and $\mathrm{BBB}$ were found to be significantly associated with the incidence of short-term adverse outcomes.

Based on the results of univariate analysis, a forward stepwise method was adopted for 19 parameters that showed significant relations for predicting short-term outcomes. Low SBP, high WBC level, HCT, concentrations of TBIL, NT-proBNP and coexistence of stage 5 chronic kidney disease (CKD) were identified as the independent predictors. Using these six risk factors and with consideration of the weighing of respective $\beta$ coefficients, we determined assigned point for each parameter, which led to a new prognostic stratification system. Because the weight associated with HCT was the lowest among parameters, we specified low HCT to 1 point and divided all weights by a factor of 1.07 then rounding them to the nearest integer. The novel scoring system was as follows: $(1 \times \mathrm{SBP}<90 \mathrm{mmHg})+(2 \times \mathrm{WBC}>$ $\left.9.2 \times 10^{9} / \mathrm{L}\right)+(1 \times \mathrm{HCT} \leq 0.407)+(2 \times \mathrm{TBIL}>34.2 \mu \mathrm{mol} / \mathrm{L})+(2 \times$ stage $5 \mathrm{CKD})+(1 \times \mathrm{NTproBNP} \geq$ $10728.9 \mathrm{ng} / \mathrm{ml})$. The univariate and multivariate logistic analysis results were listed in Table 2. 
Table 2: Odds ratios of covariates for primary endpoint in derivation cohort and model definitions $(n=1014)$

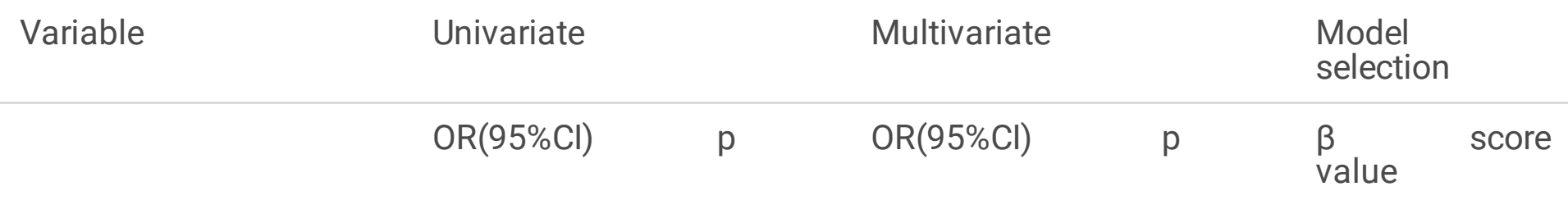

$\begin{array}{lll}\text { Female gender } & 0.838(0.576- & 0.358 \\ & 1.221) & \\ \text { Age } & 0.993(0.983- & 0.183 \\ & 1.003) & \\ \text { age } \geq 75 \text { years } & 0.923(0.576- & 0.738 \\ & 1.478) & \end{array}$

$\operatorname{BMI}\left(\mathrm{kg} / \mathrm{m}^{2}\right)$

Normal

$0 \quad 1$

$\begin{array}{lll}\text { Underweight } & 1.713(0.970- & 0.064 \\ \text { Overweight } & 3.024) & 0.375 \\ \text { Obese } & 0.810(0.509- & \\ & 1.289) & 0.162 \\ & 0.651(0.357- & \\ & 1.188) & \\ \text { GCS } & 1.875(1.490- & <0.001 \\ & 2.357) & \end{array}$

Temperature

0

0.999

SBP

$\mathrm{SBP}<90 \mathrm{mmHg}$

$5.927(2.75-\quad<0.001$ 12.762)

$4.636(1.881-$

0.001

$1.534 \quad 1$

$\mathrm{SBP} \geq 140 \mathrm{mmHg}$

1.403(0.765- 0.274

2.575)

11.426)

0.943(0.352- $\quad 0.908$

2.530)

$\mathrm{HR}(\mathrm{bpm})$

$70 \leq \mathrm{HR}<110$

0

1

$\mathrm{HR}<55$

$1.17(0.574-$

2.386)

$55 \leq \mathrm{HR}<70$

$0.848(0.541-$

1.33)

$110 \leq H R<159$

2.142(1.228- $\quad 0.007$

3.736)

$\mathrm{RR}\left(\mathrm{min}^{-1}\right)$ 


\begin{tabular}{lll}
\hline $24<\mathrm{RR} \leq 34$ & $\begin{array}{l}1.385(0.631- \\
\end{array}$ & 0.461 \\
$\mathrm{RR}>34$ & & 1 \\
$\mathrm{pH}$ & & 1 \\
& $\begin{array}{l}0.322(0.078- \\
1.333)\end{array}$ & 0.118 \\
& &
\end{tabular}

$\mathrm{PaO}_{2}$

\begin{tabular}{lll}
$60<\mathrm{PaO}_{2} \leq 70$ & $0.580(0.213-$ & 0.287 \\
& $1.581)$ & \\
\hline $55<\mathrm{PaO}_{2} \leq 60$ & $1.181(0.41-$ & 0.758 \\
& $3.404)$ & \\
$\mathrm{PaO}_{2} \leq 55$ & $0.706(0.191-$ & 0.602 \\
& $2.614)$ &
\end{tabular}

$A B$

$\begin{array}{lll}A B<22 \mathrm{mmol} / / & 2.017(1.295- & 0.002 \\ & 3.142) & \\ A B>28 \mathrm{mmol} / / & 1.975(1.193- & 0.008 \\ & 3.272) & \end{array}$

Lactic acid $>2.1 \mathrm{mmol} / \mathrm{l} \quad 3.047(1.904-\quad<0.001$ 4.876)

Serum

$2.530(1.742-\quad<0.001$

sodium $<136.1 \mathrm{mmol} / \mathrm{l} \quad 3.674$ )

Serum potassium

Hypokalemia

$0.797(0.497-\quad 0.345$

1.277)

Hyperkalemia

4.55(1.513- $\quad 0.007$

13.682)

$\mathrm{WBC}>9.2 \times 10^{9} / \mathrm{L}$

6.036(4.151- $\quad<0.001$

8.776)

6.742(3.719- $\quad<0.001 \quad 1.908 \quad 2$ 12.223)

Anemia

$1.512(1.052-\quad 0.025$

$\mathrm{HCT} \leq 40.7 \%$

2.174)

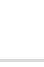

TBIL $>34.2 \mu \mathrm{mol} / \mathrm{I}$

$1.96(1.365-\quad<0.001$

2.814)

$\begin{array}{llll}2.915(1.598- & <0.001 & 1.070 \quad 1\end{array}$

$3.037(2.111-\quad<0.001$

4.370)

$5.929(3.225-$

10.899)

SUA $>547.9 \mu \mathrm{mol} / /$

$2.662(1.850-\quad<0.001$

D-dimer>0.92mg/l

3.830区

4.018(2.651- $\quad<0.001$

Page $10 / 22$ 
6.090)

$\begin{array}{lll}\text { INR }>1.145 & 3.354(2.195- & <0.001 \\ & 5.124) & \\ \text { hs-TNI } & 1.041(0.988- & 0.136 \\ & 1.096) & \end{array}$

LVEF

$\begin{array}{lll}\text { HFpEF } & 0 & 1 \\ \text { HFmrEF } & \begin{array}{ll}0.548(0.281- \\ \text { 1.068) }\end{array} & 0.077 \\ \text { HFrEF } & \begin{array}{ll}0.936(0.621- \\ \text { 1.411) }\end{array} & 0.752 \\ & & \end{array}$

\section{PASP}

\begin{tabular}{|c|c|c|}
\hline PASP $\leq 30 \mathrm{mmHg}$ & 0 & 1 \\
\hline 30هPASP $\leq 50 \mathrm{mmHg}$ & $\begin{array}{l}1.078(0.671- \\
1.732)\end{array}$ & 0.757 \\
\hline $50 ه \mathrm{PASP} \leq 70 \mathrm{mmHg}$ & $\begin{array}{l}0.965(0.602- \\
1.547)\end{array}$ & 0.883 \\
\hline PASP $\otimes 70 \mathrm{mmHg}$ & $\begin{array}{l}2.638(1.381- \\
5.039)\end{array}$ & 0.003 \\
\hline Pleural effusion & $\begin{array}{l}2.016(1.408- \\
2.887)\end{array}$ & $<0.001$ \\
\hline $\mathrm{AF}$ & $\begin{array}{l}0.830(0.567- \\
1.216)\end{array}$ & 0.34 \\
\hline BBB & $\begin{array}{l}0.756(0.480- \\
1.190)\end{array}$ & 0.227 \\
\hline
\end{tabular}

\begin{tabular}{|c|c|c|c|c|c|}
\hline eGFR $\geq 90$ & 0 & 1 & 0 & 1 & \\
\hline $60 \leq e G F R<90$ & $\begin{array}{l}0.940(0.502- \\
1.760)\end{array}$ & 0.846 & $\begin{array}{l}0.516(0.217- \\
1.226)\end{array}$ & 0.134 & \\
\hline $30 \leq e G F R<60$ & $\begin{array}{l}1.745(1.014- \\
3.003)\end{array}$ & 0.044 & $\begin{array}{l}1.205(0.555- \\
2.615)\end{array}$ & 0.638 & \\
\hline $15 \leq \mathrm{eGFR}<30$ & $\begin{array}{l}2.412(1.210- \\
4.808)\end{array}$ & 0.012 & $\begin{array}{l}0.773(0.251- \\
2.378)\end{array}$ & 0.653 & \\
\hline eGFR<15 & $\begin{array}{l}6.395(2.23- \\
18.334)\end{array}$ & 0.001 & $\begin{array}{l}5.374(1.116- \\
25.881)\end{array}$ & 0.036 & 1.681 \\
\hline
\end{tabular}

NT-proBNP(ng/ml) 


\begin{tabular}{|c|c|c|c|c|c|c|}
\hline NT-proBNP<2171.3 & 0 & 1 & 0 & 1 & & \\
\hline $\begin{array}{l}2171.3 \leq N T- \\
\text { proBNP<4966.5 }\end{array}$ & $\begin{array}{l}1.593(0.724- \\
3.505)\end{array}$ & 0.247 & $\begin{array}{l}1.517(0.583- \\
3.949)\end{array}$ & 0.393 & & \\
\hline $\begin{array}{l}4966.5 \leq N T- \\
\text { proBNP<10728.9 }\end{array}$ & $\begin{array}{l}2.018(0.943- \\
4.320)\end{array}$ & 0.071 & $\begin{array}{l}0.867(0.324- \\
2.320)\end{array}$ & 0.777 & & \\
\hline NT-proBNP $\geq 10728.9$ & $\begin{array}{l}6.049(3.03- \\
12.073)\end{array}$ & $<0.001$ & $\begin{array}{l}2.920(1.188- \\
7.179)\end{array}$ & 0.02 & 1.072 & 1 \\
\hline
\end{tabular}

\subsection{Discrimination and calibration of the new score}

In the derivation cohort, the $\mathrm{C}$ statistic of new scoring system was $0.794(95 \% \mathrm{Cl} 0.753$ to $0.836, \mathrm{p}<$ 0.001). Among the validation patients, since cases with scores of 5 or higher were limited, we combined them into one group for subsequent analysis. The incidence of adverse outcomes increased from $0 \%$ for score of 0 to $7.5 \%, 8 \%, 20.4 \%, 10 \%$ and $45.7 \%$ for score of $1,2,3,4$, and 5 points or higher. The scores of the validation cohort and the incidence of primary endpoint events were shown in Fig. 1.

Using receiver operating characteristics analysis, the $\mathrm{C}$ statistics were calculated for comparison of the discriminative power between the new score and other established systems. The $\mathrm{C}$ statistic for our new score was 0.758 ( $95 \% \mathrm{Cl} 0.677$ to $0.838, \mathrm{p}<0.001$ ), whereas for APACHE $\square$ was $0.598(95 \% \mathrm{Cl} 0.496$ to $0.700, p=0.058)$, for ADEHER risk tree[4] and AHEAD score was $0.631(95 \% \mathrm{Cl} 0.529$ to $0.733, \mathrm{p}=0.011)$ and $0.540(95 \% \mathrm{Cl} 0.442$ to $0.638, \mathrm{p}=0.439)$ respectively, demonstrating that our system had a better predictive power for short-term outcomes in critically-ill ADHF patients. The comparison of these four scores were shown in Fig. 2. The calibration of the system was evaluated with the Hosmer-Lemeshow goodness-of-fit test. In the validation cohort, the new scoring system demonstrated a good calibration ( $X 2$ $=6.681, p=0.463)$ for detecting high-risk ADHF patients admitted to ED. The calibration plots were shown in Fig. 3.

Furthermore, we attempted to predict the occurrence of heart transplantation with the new system. The $C$

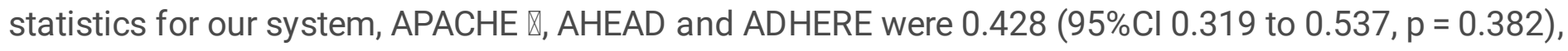
$0.358(95 \% \mathrm{Cl} 0.234$ to $0.482, \mathrm{p}=0.084), 0.480(95 \% \mathrm{Cl} 0.336$ to $0.624, \mathrm{p}=0.809)$ and $0.501(95 \% \mathrm{Cl} 0.382$ to $0.621, p=0.986)$. None of them showing enough ability for predicting the considerations for HTx selection.

\section{Discussion}

In the present study of Chinese patients in a single heart center ICU setting, we developed and validated a predictive model based on physical examinations and laboratory testing within 24 hours after admission. We found that six parameters were significantly associated with poor short-term outcome: (A)low systolic 
blood pressure (SBP $<90 \mathrm{mmHg}$ ), (B)increasing white blood cell (WBC $\left.>9.2 \times 10^{9} / \mathrm{L}\right)$, (C)low hematocrit (HCT $\leq 0.407$ ), (D)abnormal liver parameter (TBIL > $34.2 \mu \mathrm{mol} / \mathrm{L}$ ), (E) NT-proBNP $\geq 10728.9 \mathrm{ng} / \mathrm{ml}$ and (F)stage 5 CKD (eGFR $<15 \mathrm{ml} / \mathrm{min} / 1.73 \mathrm{~m}^{2}$ ). In comparison, several commonly used existing systems did not exhibit an adequate ability to predict in-hospital outcomes. The new risk score might aid in the identification of patients with ADHF at risk for the incidence of in-hospital death, cardiac arrest or use of mechanical support devices.

\subsection{The predictive elements for ADHF}

Hypotension is significantly associated with increased mortality in AHF patients. The clinical importance of SBP has previously been considered and prognostic scores such as ADHERE ${ }^{[4]}, \mathrm{AHFI}^{[15]}$ and GWTG$\mathrm{HF}^{[16]}$ have been created. Gheorghiade et al. reported that a systolic pressure under $120 \mathrm{mmHg}$ at the time of admission was associated with a poor prognosis compared with a systolic pressure over $120 \mathrm{mmHg}^{[17]}$. Previously, a multicenter acute heart failure registry study also indicated that low admission SBP is an independent predictor of mortality in patients with AHF both in HFpEF and HFrEF, regardless of age ${ }^{[18]}$. Similarly, we identified hypotension $(\mathrm{SBP}<90 \mathrm{mmHg}$ ) was independently associated with the incidence of short-term poor prognosis and was included in the new scoring system.

Elevated leukocytes often reflects the existence of inflammatory response. In the present study, it also emerged as an independent risk predictor and was one of the most important determinants of the shortterm prognosis. There is evidence to suggest an association between leukocytes and HF development and outcomes. Elevated leukocyte level $\left(9 \times 10^{3} \mathrm{cells} / \mathrm{mm}^{3}\right)$ has been recently identified as an independent predictor of in-hospital mortality in patients with acute non-ischemic HF and of long-term

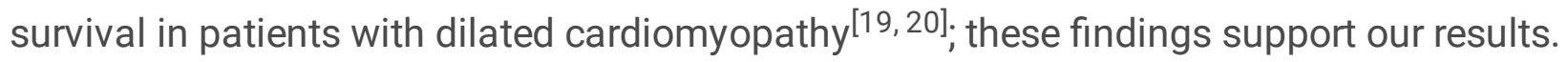

Anemia is a frequent co-morbidity in patients with acute heart failure. Several studies have reported that the presence or development of anemia is correlated with increased mortality and morbidity and with higher hospitalization rates, irrespectively of age, gender, diabetes or the NYHA functional class in chronic HF patients ${ }^{[21,22]}$. Von Haehling $S$ et al. has found, in a study of 627 AHF patients, that moderate or severe anemia predicts a significantly increased 12-month mortality after adjusting for other risk factors ${ }^{[22]}$. However most previous studies used the hemoglobin level as a marker of anemia, the relationship between hematocrit and ADHF remains to be elucidated. The present study showed that hematocrit had a better predictive power than hemoglobin and was employed in the new scoring system.

Abnormal liver function test results are often observed in heart failure. According to China heart failure(China-HF) registry, elevated total bilirubin is an independent predictor of adjusted in-hospital mortality ${ }^{[23]}$. In the Acute Study of Clinical Effectiveness of Nesiritide in Decompensated Heart Failure(ASCEND-HF), compared with normal bilirubin levels, abnormal total bilirubin was associated with increased 30-day mortality or HF rehospitalization and 180 -day mortality ${ }^{[24]}$. Nevertheless, few risk 
stratification systems previously investigated select TBIL as a marker of impaired liver function. Our analysis showed close correlation between TBIL on admission and short-term outcomes.

The interactions between heart and kidney are strong and complicated, by which acute or chronic dysfunction in one organ may induce dysfunction in the other. As previously shown, renal dysfunction is a strong prognosis predictor of AHF. For example, in the data from AHEAD registry, patients with eGFR < $30 \mathrm{ml} / \mathrm{min}$ on admission had a poor prognosis during hospitalization and long-term follow-ups ${ }^{[10]}$. In another retrospective study, with 104794 AHF admissions, abnormal eGFR on admission was proved to be a significant predictor of mortality and readmission risk ${ }^{[25]}$, in keeping with the fact that nearly all established scores took renal function into account ${ }^{[7]}$. For this score evaluation, we used eGFR calculated by Chinese version of the MDRD equation instead of serum creatinine as the indicator for estimating renal function, scoring 2 points if less than $15 \mathrm{ml} / \mathrm{min} / 1.73 \mathrm{~m}^{2}$ in both sex.

In addition to the above clinical and laboratory results, plasma level of $\mathrm{N}$-terminal propeptide brain natriuretic peptide played a critical role in our analysis. The 2016 ESC guideline recommends it as an initial diagnostic test especially for excluding the diagnosis of HF with a high negative predictive value $^{[12]}$. A meta-analysis of ADHF patients has confirmed that NT-proBNP is an independent predictor of mortality both in all-cause and cardiovascular death despite different cut points, time intervals and prognostic models ${ }^{[26]}$. More recently, Biljana Stojcevski et al. reported that discharge NT-proBNP should be assessed to detect the AHF patients with higher risk of short- and long-term death ${ }^{[27]}$. Although current studies employed different cut-off values for NT-proBNP, we used quartiles for multivariate analysis, which showed that only patients with the highest plasma concentration of NT-proBNP was related to poorer in-hospital outcomes scoring 1 point in the new system.

\subsection{The unique potential value of the new score}

To improve the prognosis for ADHF, it is crucial to identify high-risk patients as a first step. Several risk stratification systems have been published for AHF previously such as the Acute Physiology and Chronic Health Evaluation(APACHE) system ${ }^{[9]}$, AHEAD score ${ }^{[10]}$, ADHERE, American Heart Association Get With the Guidelines-Heart Failure (GWTG-HF) ${ }^{[16]}$, ACUTE HF score ${ }^{[11]}$ and AHFI ${ }^{[15]}$. However, there are several limitations of these systems. Firstly, existing clinical predictive models for AHF were largely derived from North America or Europe, the performance of scoring systems varied substantially across different world regions. A recent study indicated that region-specific recalibrations were needed for AHF patients ${ }^{[28]}$. Secondly, many scores were established more than ten years ago. With the development and application of new diagnosing techniques and arising biomarkers, some important clinical indicators should be brought into reevaluation such as NT-proBNP, hs-TNI, D-dimer.

There are several noteworthy features of the present investigation: Because of the exclusion criteria not covering LVEF, it was carried out in a cohort of ADHF patients containing not only HFrEF but also HFpEF and HFmrEF often ignored in other studies. And it offered a relatively comprehensive system for evaluating in-hospital outcomes for critically-ill ADHF patients, due to the complete analysis of clinical, 
biochemical, electrocardiographic and echocardiographic parameters. Considering the incompleteness and availability of past medical history in practical ED situations, we did not highlight past diseases in building the new scoring system. Also, we utilized logistic regression instead of regression tree analysis, hence constructed a quantifiable tool to reach a better predictive accuracy. Moreover, the final model consisting of six easy-to-obtain indexes with a simple calculation method was relatively convenient to identify high-risk populations and aid to determine whether an emergency ADHF should be admitted to ICU department or treated in ED. For these reasons, our new score might represent a practical and efficient approach to the critically-ill patients commonly hospitalized for ADHF.

\subsection{New score and heart transplantation}

Although this new system showed a satisfactory predictive power for the composite endpoint, it cannot accurately predict HTx. The candidacy for HTx was assessed carefully in Fuwai hospital. Elderly and frail patients with ADHF who failed optimal medical management and mechanical circulatory support often suffered from malnutrition, immune dysfunction and multiple organ failure. They were obviously unsuitable for operations. It was understandable that the score was unparallel to the consideration of HTx. Secondly, the selection for HTx was associated with economic conditions, social support and psychological condition.

\subsection{Study limitations}

This study presents a potential model for triaging emergency department ADHF patients for intensive care unit. Also, it had several limitations. First, our database consisted of a cohort of patients from a single cardiovascular hospital, and the study population included only Chinese patients. The participants evaluated was limited to patients admitted only to the ICU, and ADHF patients who were then admitted to other wards were not enrolled. Although an internal validation was performed by bootstrapping techniques in the same population, the results should be carefully interpreted when applied to external validation studies. Second, the composite endpoint of our study was in-hospital death or cardiac arrest or clinical application of mechanical support devices. The selected 6 parameters demonstrated good ability to distinguish patients with high risk of short-term adverse events. Due to lack of follow-ups after discharge, the ability of our scoring system to predict post-discharge and long-term prognosis was still uncertain. Third, the individual clinical data was collected at the time of admission without counting the effects of pre-hospital managements, such as the widely used inotropic drugs for ADHF, which may influence admission blood pressure and heart rate.

\section{Conclusions}

Existing predictive systems did not demonstrate enough ability to evaluate the incidences of short-term adverse events in critically-ill ADHF in Chinese population. Our new scoring system including SBP, white blood cell count, hematocrit, total bilirubin, estimated glomerular filtration rate and NT-proBNP might provide a practical tool for daily risk stratification of ADHF patients, irrespective of its etiology. 


\section{Abbreviations}

ADHF

acute decompensated heart failure; ED:emergency department; SBP:systolic blood pressure; HCT:hematocrit; WBC:white blood cell; TBIL:total bilirubin; eGFR:estimated glomerular filtration rate; HF:heart failure; ACC:American college of Cardiology; ICU:intensive care unit; APACHE:Acute Physiology and Chronic Health Evaluation; ED:emergency department; CHF:chronic heart failure; GCS:Glasgow coma scale; BMI:body mass index; AF:atrial fibrillation; BBB:bundle branch block; LVEF:left ventricular ejection fraction; PASP:pulmonary arterial systolic pressure; $A B$ :actual bicarbonate; Hb:hemoglobin; HCT:hematocrit; INR:international normalized ratio; SUA:serum uric acid; hs-TNI:high-sensitivity troponin l; NT-proBNP:N-terminal pro-B-type natriuretic peptide; IABP:intra-aortic balloon pumps; ECMO:extracorporeal membrane oxygenation; HTx:heart transplantation; HR:heart rate; RR:respiratory rate; ROC:receiver-operating characteristic; ORs:odds ratios; Cl:confidence interval; HFrEF:heart failure with reduced ventricular ejection fraction; HFpEF:heart failure with preserved ejection fraction; HFmrEF:heart failure with mid-range ejection fraction.

\section{Declarations}

Ethics approval and consent to participate

The study was approved by the ethics committee of Fuwai hospital and obeyed the Declaration of Helsinki (No. 2017YFC0908802). All patients have provided written consent to participate in this study.

Consent for publication

Not applicable

Availability of data and materials

The datasets used and analysed during the current study are available from the corresponding author on reasonable request.

Competing interests

The authors declare that they have no competing interests.

Funding

No funding.

Authors` contributions

Ran Mo collected the data, performed the statistical analysis and was a major contributor in writing this manuscript. Li-tian Yu and Hui-qiong Tan designed the study and revised this manuscript. Yang Wang 
participated in statistical guidance and sample size calculation. Yan-min Yang, Yan Liang and Jun Zhu provided clinical advice on study design. All authors read and approved the final manuscript.

\section{Acknowledgements}

The authors wish to thank all patients taking part in the study.

\section{References}

[1] Nieminen MS, Brutsaert D, Dickstein K, Drexler H, Follath F, Harjola VP, et al. EuroHeart Failure Survey II (EHFS II): a survey on hospitalized acute heart failure patients: description of population. European heart journal. 2006;27(22):2725-36.

[2] Abraham WT, Adams KF, Fonarow GC, Costanzo MR, Berkowitz RL, LeJemtel TH, et al. In-hospital mortality in patients with acute decompensated heart failure requiring intravenous vasoactive medications: an analysis from the Acute Decompensated Heart Failure National Registry (ADHERE). J Am Coll Cardiol. 2005;46(1):57-64.

[3] Bueno H, Ross JS, Wang Y, Chen J, Vidán MT, Normand SL, et al. Trends in length of stay and shortterm outcomes among Medicare patients hospitalized for heart failure, 1993-2006. Jama. 2010;303(21):2141-7.

[4] Fonarow GC, Adams KF, Jr., Abraham WT, Yancy CW, Boscardin WJ. Risk stratification for in-hospital mortality in acutely decompensated heart failure: classification and regression tree analysis. Jama. 2005;293(5):572-80.

[5] Hollenberg SM, Warner Stevenson L, Ahmad T, Amin VJ, Bozkurt B, Butler J, et al. 2019 ACC Expert Consensus Decision Pathway on Risk Assessment, Management, and Clinical Trajectory of Patients Hospitalized With Heart Failure: A Report of the American College of Cardiology Solution Set Oversight Committee. J Am Coll Cardiol. 2019;74(15):1966-2011.

[6] Ouwerkerk W, Voors AA, Zwinderman AH. Factors influencing the predictive power of models for predicting mortality and/or heart failure hospitalization in patients with heart failure. JACC Heart failure. 2014;2(5):429-36.

[7] Passantino A, Monitillo F, lacoviello M, Scrutinio D. Predicting mortality in patients with acute heart failure: Role of risk scores. World J Cardiol. 2015;7(12):902-11.

[8] Jentzer JC, van Diepen S, Murphree DH, Ismail AS, Keegan MT, Morrow DA, et al. Admission diagnosis and mortality risk prediction in a contemporary cardiac intensive care unit population. American Heart Journal. 2020;224:57-64.

[9] Knaus WA, Draper EA, Wagner DP, Zimmerman JE. APACHE II: a severity of disease classification system. Crit Care Med. 1985;13(10):818-29. 
[10] Spinar J, Jarkovsky J, Spinarova L, Mebazaa A, Gayat E, Vitovec J, et al. AHEAD score-Long-term risk classification in acute heart failure. Int J Cardiol. 2016;202:21-6.

[11] Cameli M, Pastore MC, De Carli G, Henein MY, Mandoli GE, Lisi E, et al. ACUTE HF score, a multiparametric prognostic tool for acute heart failure: A real-life study. Int J Cardiol. 2019;296:103-8.

[12] Ponikowski P, Voors AA, Anker SD, Bueno H, Cleland JGF, Coats AJS, et al. 2016 ESC Guidelines for the diagnosis and treatment of acute and chronic heart failure: The Task Force for the diagnosis and treatment of acute and chronic heart failure of the European Society of Cardiology (ESC)Developed with the special contribution of the Heart Failure Association (HFA) of the ESC. European heart journal. 2016;37(27):2129-200.

[13] Ma YC, Zuo L, Chen JH, Luo Q, Yu XQ, Li Y, et al. Modified glomerular filtration rate estimating equation for Chinese patients with chronic kidney disease. Journal of the American Society of Nephrology : JASN. 2006;17(10):2937-44.

[14] Sullivan LM, Massaro JM, D'Agostino RB. Presentation of multivariate data for clinical use: The Framingham Study risk score functions. Statistics in Medicine. 2004;23(10):1631-60.

[15] Auble TE, Hsieh M, Gardner W, Cooper GF, Stone RA, McCausland JB, et al. A prediction rule to identify low-risk patients with heart failure. Academic emergency medicine : official journal of the Society for Academic Emergency Medicine. 2005;12(6):514-21.

[16] Peterson PN, Rumsfeld JS, Liang L, Albert NM, Hernandez AF, Peterson ED, et al. A validated risk score for in-hospital mortality in patients with heart failure from the American Heart Association get with the guidelines program. Circulation Cardiovascular quality and outcomes. 2010;3(1):25-32.

[17] Gheorghiade M, Abraham WT, Albert NM, Greenberg BH, O'Connor CM, She L, et al. Systolic blood pressure at admission, clinical characteristics, and outcomes in patients hospitalized with acute heart failure. Jama. 2006;296(18):2217-26.

[18] Al-Lawati JA, Sulaiman KJ, Al-Zakwani I, Alsheikh-Ali AA, Panduranga P, Al-Habib KF, et al. Systolic Blood Pressure on Admission and Mortality in Patients Hospitalized With Acute Heart Failure:

Observations From the Gulf Acute Heart Failure Registry. Angiology. 2017;68(7):584-91.

[19] Summers C, Rankin SM, Condliffe AM, Singh N, Peters AM, Chilvers ER. Neutrophil kinetics in health and disease. Trends in immunology. 2010;31(8):318-24.

[20] Riad A, Weitmann K, Herda LR, Empen K, Gross S, Nauck M, et al. Initial white blood cell count is an independent risk factor for survival in patients with dilated cardiomyopathy. Int $\mathrm{J}$ Cardiol. 2013;168(2):1207-13.

[21] Horwich TB, Fonarow GC, Hamilton MA, MacLellan WR, Borenstein J. Anemia is associated with worse symptoms, greater impairment in functional capacity and a significant increase in mortality in 
patients with advanced heart failure. J Am Coll Cardiol. 2002;39(11):1780-6.

[22] von Haehling S, Schefold JC, Hodoscek LM, Doehner W, Mannaa M, Anker SD, et al. Anaemia is an independent predictor of death in patients hospitalized for acute heart failure. Clinical research in cardiology : official journal of the German Cardiac Society. 2010;99(2):107-13.

[23] Zhang Y, Zhang J, Butler J, Yang X, Xie P, Guo D, et al. Contemporary Epidemiology, Management, and Outcomes of Patients Hospitalized for Heart Failure in China: Results From the China Heart Failure (China-HF) Registry. J Card Fail. 2017;23(12):868-75.

[24] Samsky MD, Dunning A, DeVore AD, Schulte PJ, Starling RC, Tang WH, et al. Liver function tests in patients with acute heart failure and associated outcomes: insights from ASCEND-HF. Eur J Heart Fail. 2016;18(4):424-32.

[25] Málek F, Oštádal P, Pařenica J, Jarkovský J, Vítovec J, Widimský P, et al. Uric acid, allopurinol therapy, and mortality in patients with acute heart failure-results of the Acute HEart FAilure Database registry. Journal of critical care. 2012;27(6):737.e11-24.

[26] Santaguida PL, Don-Wauchope AC, Oremus M, McKelvie R, Ali U, Hill SA, et al. BNP and NT-proBNP as prognostic markers in persons with acute decompensated heart failure: a systematic review. Heart Failure Reviews. 2014;19(4):453-70.

[27] Stojcevski B, Celic V, Navarin S, Pencic B, Majstorovic A, Sljivic A, et al. The use of discharge haemoglobin and NT-proBNP to improve short and long-term outcome prediction in patients with acute heart failure. European heart journal Acute cardiovascular care. 2017;6(8):676-84.

[28] Wessler BS, Ruthazer R, Udelson JE, Gheorghiade M, Zannad F, Maggioni A, et al. Regional Validation and Recalibration of Clinical Predictive Models for Patients With Acute Heart Failure. Journal of the American Heart Association. 2017;6(11).

\section{Figures}




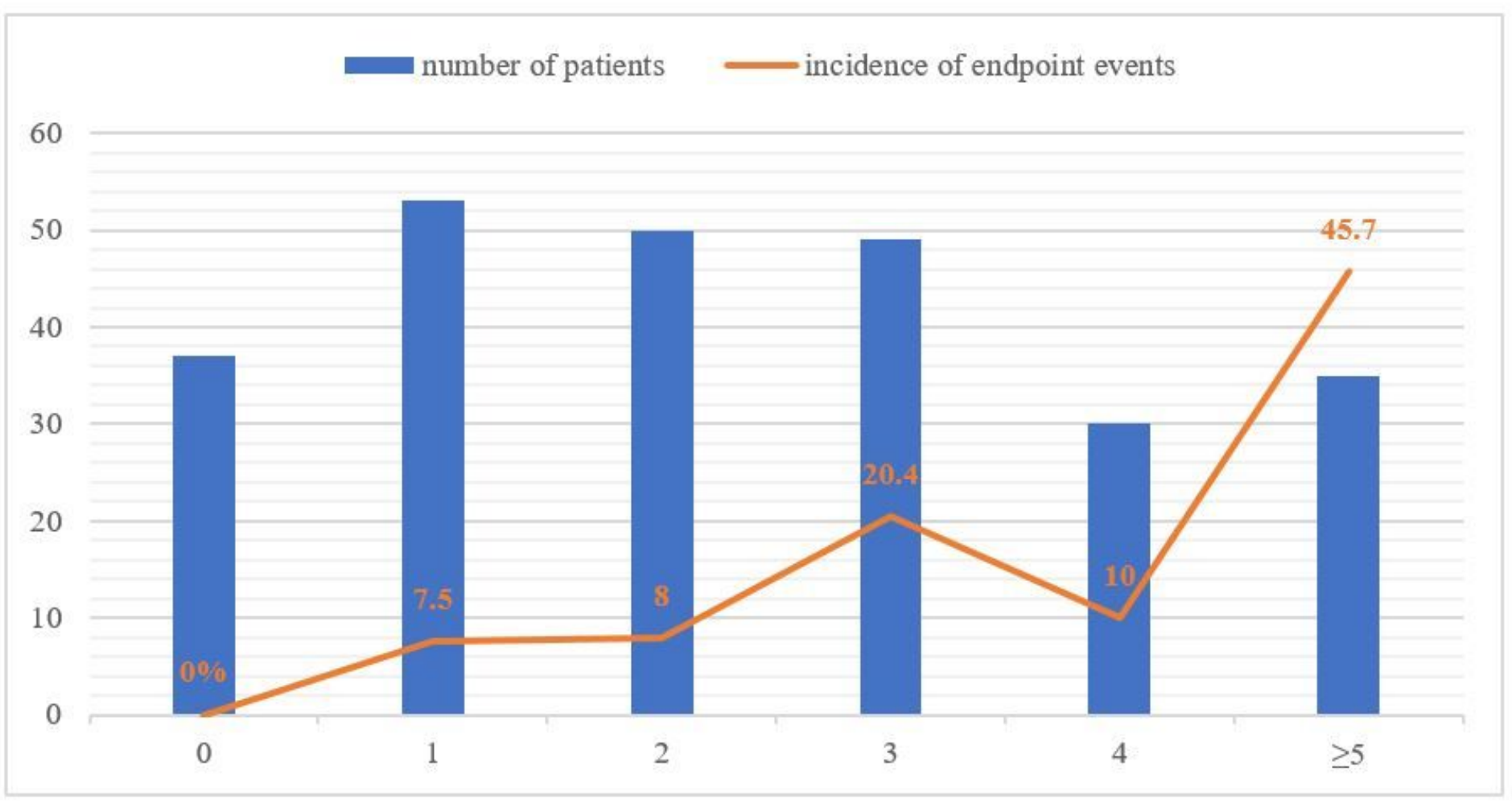

Figure 1

Prevalence of the different scores and incidence of adverse events. Blue bars represent the number of patients for each score. The orange line represents the incidence rates according to the new score. 


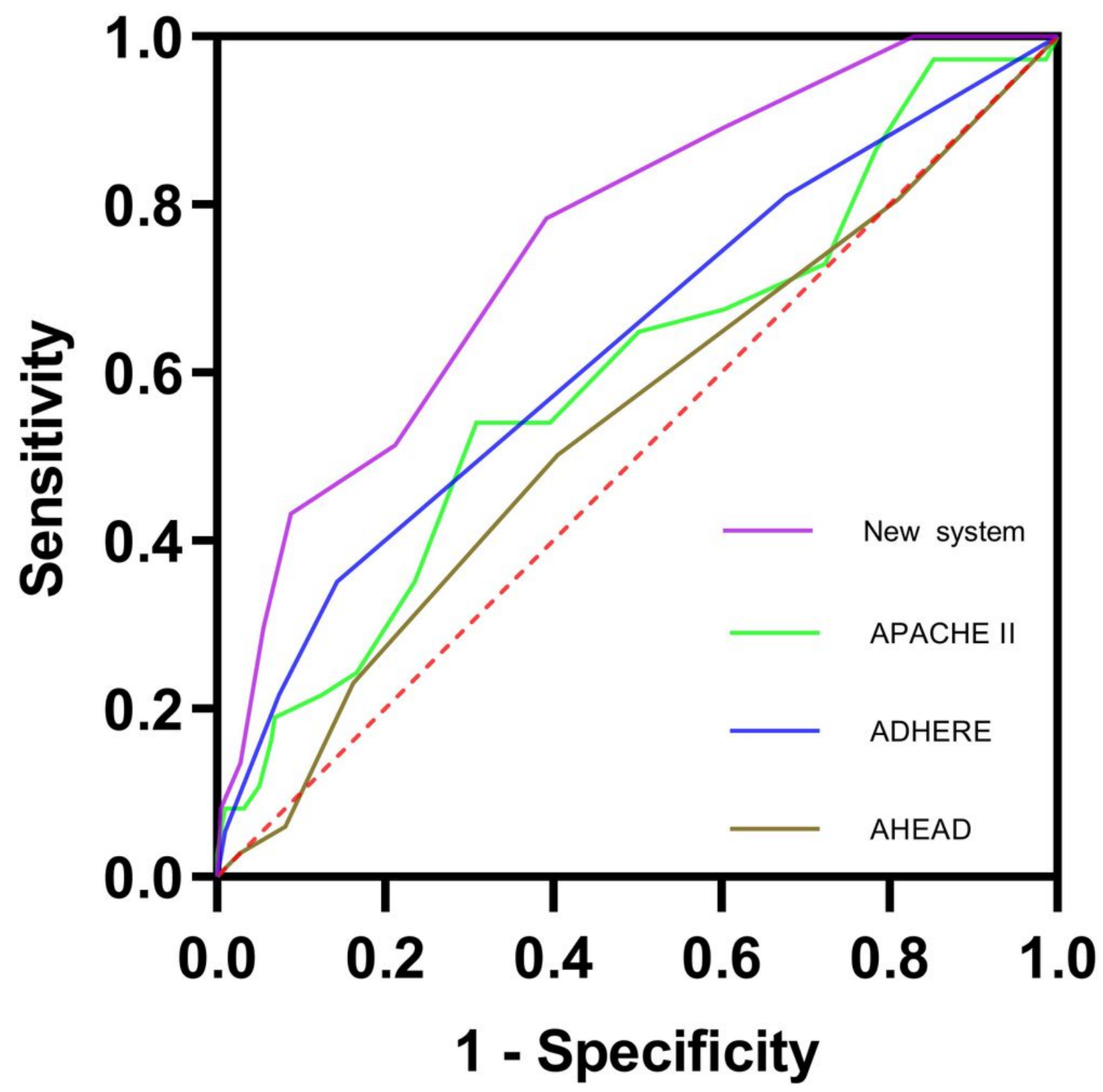

Figure 2

Receiver operating characteristic curves for different scoring systems. The green line represents APACHE $\bigotimes$. The blue line represents ADHERE risk tree. The brown line represents AHEAD score. The purple line presents the new scoring system. 


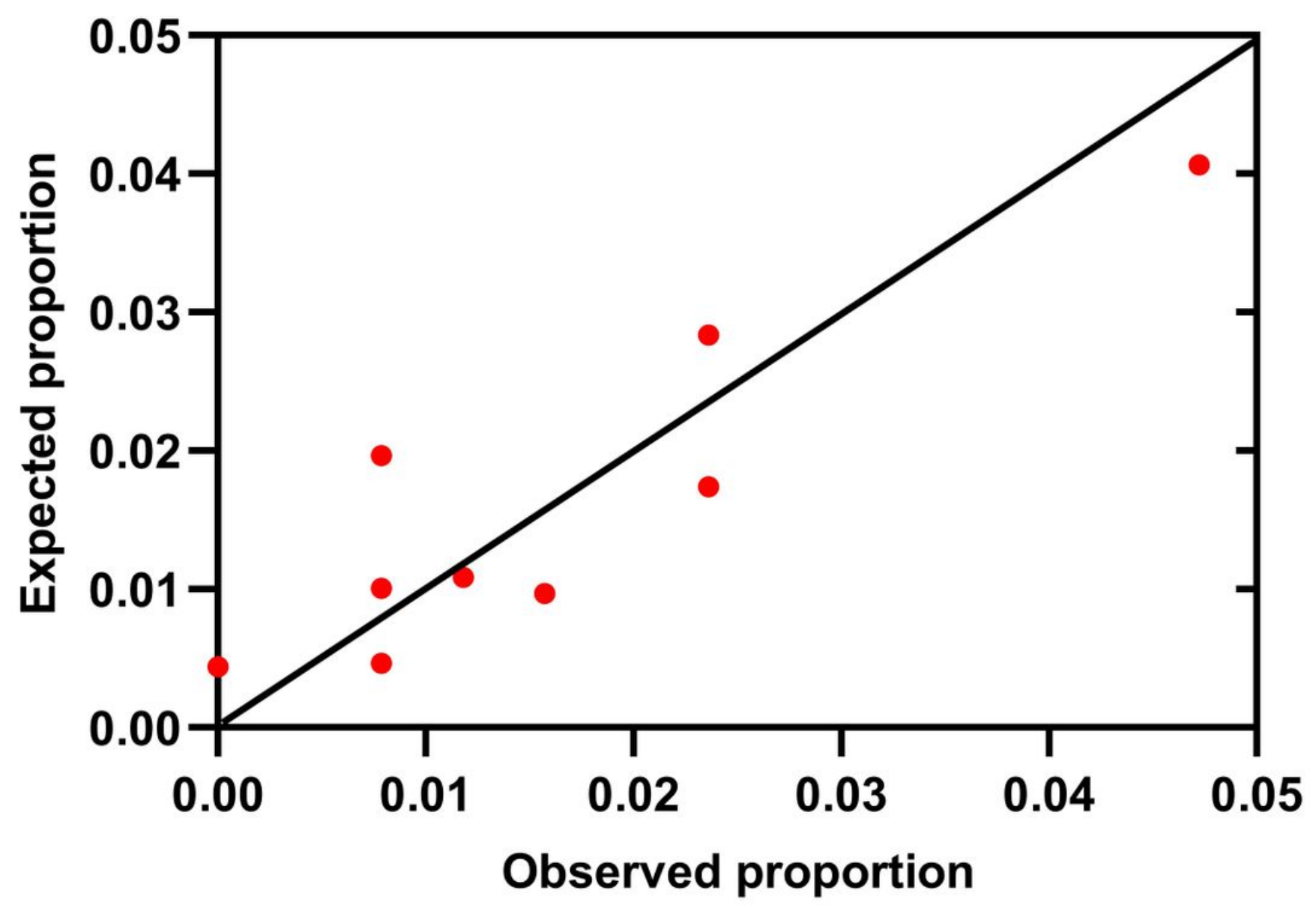

Figure 3

Calibration plots showing the agreement between predicted and observed probabilities for primary endpoints. 